Journal of Case Reports 2018;8(3):223-225

\title{
Atypical Proximal Femoral Osteoid Osteoma
}

\author{
Suresh K M Annamalai \\ Department of Orthopaedics, Manipal Hospital, Bangalore, Karnataka, India.
}

Corresponding Author:

Dr. Suresh K M Annamalai

Email: drsureshkumar.ortho@gmail.com

This is an Open Access article distributed under the terms of the Creative Commons Attribution License (creativecommons.org/ licenses/by/3.0).

Received Accepted Published

November 6, 2017 August 27, 2018 September 25, 2018

\begin{abstract}
Background: Osteoid-osteoma is the third most common benign bone neoplasm, occurring predominantly in young which can cause debilitating pain. In most cases, the patients presents with pain that is worsened at night and is alleviated with the use of nonsteroidal anti-inflammatory drugs. Conventional radiography or computed tomography shows a well-defined lytic area representing the vascular central nidus, surrounded by sclerosis and cortical thickening. For symptomatic patients the treatment is resection and curettage and the results are generally favourable. Case Report: An unusual case of osteoid osteoma is presented which had a diagnosis dilemma and her symptoms were cured incidentally by curettage of the nidus. Conclusion: Osteoid osteoma can present in unusual way and a high index of suspicion is essential for appropriate management.
\end{abstract}

Keywords: Bone Neoplasms, Curettage, Osteoid osteoma, Pain, Sclerosis, Tomography.

\section{Introduction}

Osteoid osteoma, an infrequent but important cause of musculoskeletal pain, is often difficult to diagnose [1]. It accounts for approximately $10 \%$ of benign bone tumors [2]. Most osteoid osteoma are found in the first three decades of life, and male/ female ratio is $2: 1$ [3]. The tumor is usually less than $1.5 \mathrm{~cm}$ in diameter and the lesion appears as a small sclerotic bone of island with a circular lucent defect called the nidus [3-5]. The proximal femur is the most common location followed by tibia, posterior element of spine, and the humerus [3]. There are three types, cortical, cancellous or the sub-periosteal and the commonest being cortical which is $>90 \%$.

Osteoid osteoma has classical presentation of dull pain that is worse at night and disappears within 20-30 minutes of treatment with nonsteroidal anti-inflammatory medication. Spinal involvement can cause abnormal alignment and neurological abnormalities. The classical radiological presentation is a radiolucent nidus surrounded by reactive sclerosis in the cortex of the bone. The four diagnostic features include a round or oval lesion, less than $2 \mathrm{~cm}$ in diameter, has a homogenous dense centre, and a 1-2 mm peripheral radiolucent zone [6]. CT is the preferred method of evaluation especially if the lesion is in the spine [4]. Bone scan commonly shows a double density sign with increase uptake centrally that distinguishes the lesion from osteomyelitis or abscess [1]. Osteoid osteoma will resolve spontaneously but take an average of 33 months [7]. If the symptoms warrant surgical intervention than surgical removal or percutaneous ablation of the nidus is indicated.

We present an unusual case of osteoid osteoma with diagnosis dilemma, and the symptoms were cured by accidental removal of nidus whilst performing core biopsy for diagnosis.

\section{Case Report}

We are reporting an unusual case of osteoid osteoma in a 35 year old young fit and active lady. This lady with persistent lower back pain and right 
groin pain for several months was referred by physician. Her main complaints were persistent dull aching pain in the lower back and right groin. No radiation of pain or any aggravating or reliving factors were present. There was no history of any previous injury and pain failed to improve with non-steroidal anti-inflammatory medications.

On clinical examination the spine, hip, knee and lower limbs were unremarkable, and the other surgical causes of groin pain like femoral hernia were ruled out. All her inflammatory parameters including white cell count, $\mathrm{C}$ reactive protein and erythrocyte sedimentation rate were within normal limits. Radiograph of the spine was normal. Radiograph of the pelvis showed $2.5 \mathrm{~cm}$ sclerosed circular lesion at the inter-trochantric region of the right femur. There was no radiolucencies within the lesion and the surrounding bone quality was normal [Fig.1]. The lesion resembled a benign lesion. MRI scan of the lumbar sacral spine was performed to rule out spinal cause of pain, which was normal.

MRI scan of the pelvis showed $2.5 \mathrm{~cm}$ well defined rounded lesion in the inter-trochanteric region of the right proximal femur [Fig.2]. Differential diagnosis of benign sclerotic or fibrotic in nature was considered including bone infarct, bone island, brodies abscess, sclerotic metastasis, long standing infarction, and atypical fibrous dysplasia. A core needle biopsy was performed under general anaesthesia with the aid of image intensifier [Fig.3] and the histopathology report showed calcified immature bone, some fragments showing scalloping and resorption. Few osteoblast and osteoclast seen but there were wide osteoids and there was appearance of nidus suggestive of osteoid osteoma.

The lady was seen in regular followup clinic and by then the pain had disappeared suggesting that the core needle biopsy has removed the nidus by chance relieving her symptoms.

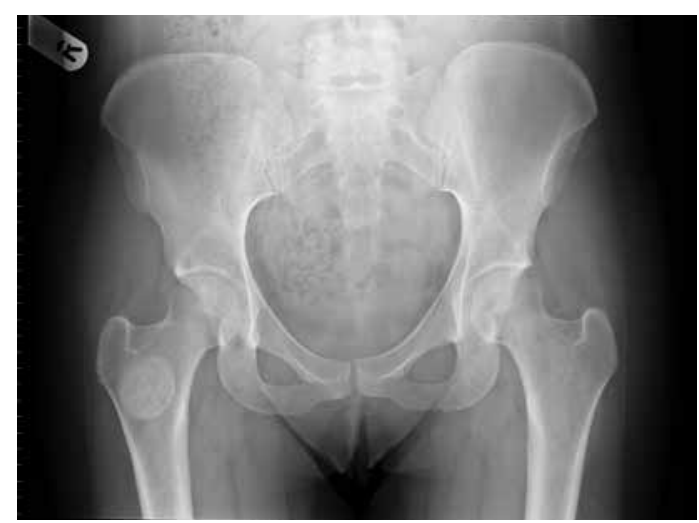

Fig.1: Conventional radiograph showing the lesion in the right proximal femur.

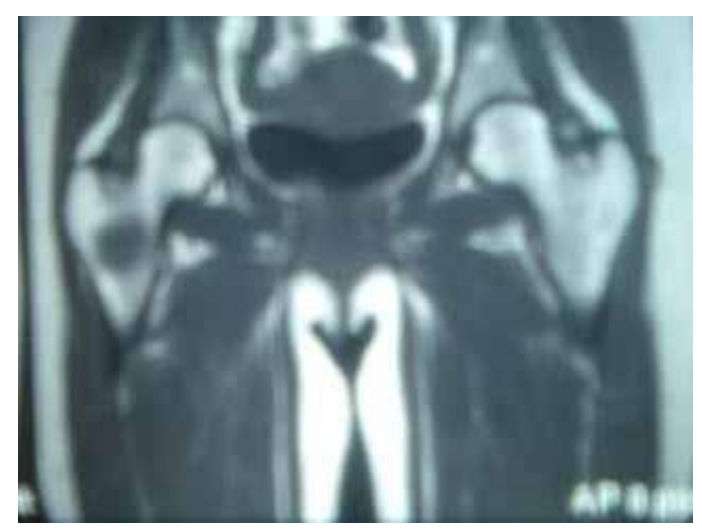

Fig.2: MRI scan of the lesion.

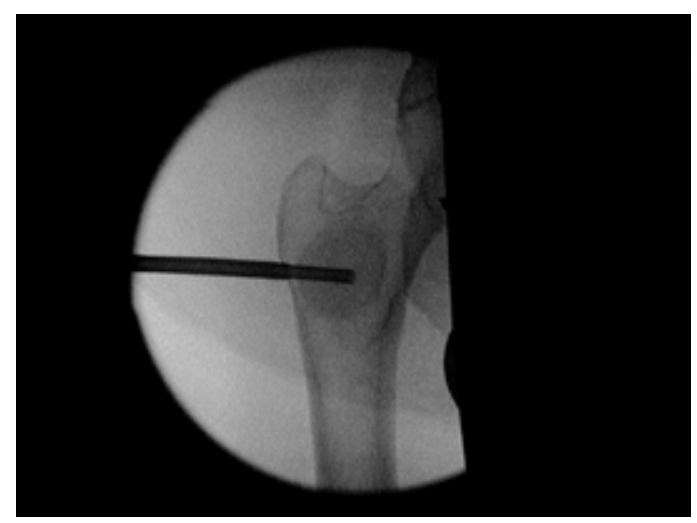

Fig.3: Core needle biopsy of the lesion.

\section{Discussion}

Osteoid osteoma is a common benign lesion, occurring predominantly in young male patients [10], and they can present in unusual place. We had 
a young lady with no classical signs and symptoms of osteoid osteoma. In this lady the lesion was in the commonest site (proximal femur) with unusual presentation. We never had the differential diagnosis of osteoid osteoma in the first instance and the diagnosis was made by histo-pathological examination. Incidentally the core needle biopsy removed the nidus and relieved her symptoms.

The plain radiograph shows the pathognomonic pattern of central radiolucency with surrounding sclerosis, and classically the pain is relieved with NSAID's, ours case did not show any of these classical findings making diagnosis more difficult. Computed tomography is an excellent imaging method to identify the central nidus of the tumor and can also be utilized for treatment, as guidance for percutaneous removal of the nidus as described by the article developed by Petrilli et al. [11].

There are few case reports with multicentric nidus reported in literature $[8,9]$. We presented an unusual case with no nidus seen on radiological imaging and osteoid osteoma diagnosis was made retrospectively with incidental finding of nidus on histopathology and complete relieve of symptoms.

Osteoid Osteoma can present in unusual way and a high index of suspicion is essential for appropriate management. These types of lesions when confirmed can be treated with computed tomography-guided percutaneous trephine removal of the nidus [10], demonstrating that this is safe and effective method for surgical resection of the lesion with reduced hospitalization time and less post-operative pain [11].
Contributors: SKMA: manuscript writing, literature search, patient management and final approval; SKMA will act as guarantor.

Funding: None; Competing interests: None stated.

\section{References}

1. Schaefer MP, Smith J. The diagnostic and therapeutic challenge of the femoral head osteoid osteoma presenting as thigh pain: A Case Report. Arch Phys Med Rehabil. 2003;84:904-905.

2. Frassica FJ, Waltrip RL, Sponseller PD, Ma LD, McCarthy EF. Clinicopathologic features and treatment of osteoid osteoma and osteoblastoma in children and adolescents. Orthop Clin North Am. 1996;27:559-574.

3. Canale TS. Campbell's operative orthopaedics. St Louis: Mosby: 2003. pp. 801-803.

4. Resnick D. Diagnosis of bone and joint disorders. Philadelphia: WB Saunders;1995. pp. 3628-3647.

5. Ward WG, Eckardt JJ, Shayestehfar S, Mirra J, Grogan T, Oppenheim W. Osteoid osteoma diagnosis and management with low morbidity. Clin Orthop. 1993;291:229-235.

6. Bloem J, Kroon H. Osseous lesions. Radiologic Clinics of North America 1993;31:261-277.

7. Kneisl JS, Simon MA, Medical management compared with operative treatment for osteoid-osteoma. J Bone Joint Surg Am. 1992;74:179-185.

8. Glynn JJ, Lichtenstein L. Osteoid osteoma with multicentric nidus: A report of two cases. J Bone Joint Surg Am. 1973;55:855-858.

9. Zmurko MG, Michael P Mott, David R Lucas, Merlin R Hamre, Peter R Miller. multicentric osteoid osteoma: A case Report; Orthopaedics: 2004;27(12):1294-1296.

10. Canella C. Osteoid osteoma: Diagnosis and treatment. Radiol Bras. 2015;48(4).

11. Petrilli M, Senerchia AA, Petrilli AS, Lederman HM, Filho RJG. Computed tomography-guided percutaneous trephine removal of the nidus in osteoid osteoma patients: experience of a single centre in Brazil, Radiol Bras. 2015;48:211-215. 